Article

\title{
Off-Center Rotation of CuPc Molecular Rotor on a Bi(111) Surface and the Chiral Feature
}

\author{
Kai Sun, Min-Long Tao, Yu-Bing Tu and Jun-Zhong Wang * \\ School of Physical Science and Technology, MOE Key Laboratory on Luminescence and Real-Time Analysis, \\ Southwest University, Chongqing 400715, China; sun.andkai@163.com (K.S.); taotaole@swu.edu.cn (M.-L.T.); \\ tuyubing@gmail.com (Y.-B.T.) \\ * Correspondence: jzwangcn@swu.edu.cn; Tel./Fax: +86-23-68252355
}

Academic Editor: Augusto C. Tomé

Received: 10 April 2017; Accepted: 2 May 2017; Published: 4 May 2017

\begin{abstract}
Molecular rotors with an off-center axis and the chiral feature of achiral CuPc molecules on a semi-metallic $\mathrm{Bi}(111)$ surface have been investigated by means of a scanning tunneling microscopy (STM) at liquid nitrogen $\left(\mathrm{LN}_{2}\right)$ temperature. The rotation axis of each CuPc molecular rotor is located at the end of a phthalocyanine group. As molecular coverage increases, the CuPc molecules are self-assembled into various nanoclusters and finally into two-dimensional (2D) domains, in which each $\mathrm{CuPc}$ molecule exhibits an apparent chiral feature. Such chiral features of the $\mathrm{CuPc}$ molecules can be attributed to the combined effect of asymmetric charge transfer between the CuPc and $\mathrm{Bi}(111)$ substrate, and the intermolecular van der Waals interactions.
\end{abstract}

Keywords: scanning tunneling microscopy (STM); CuPc molecules; off-center rotation; semi-metallic $\mathrm{Bi}$; chiral feature

\section{Introduction}

As an archetype molecule with organic semiconducting properties in the bulk, transition-metal phthalocyanines (TMPc) have attracted considerable interest due to their potential applications in organic electronic devices in the past few years [1-3]. Because of their high thermal stability, electronic structure, and symmetric cross-like geometrical structure in Figure 1a, TMPc can be used in organic solar cells [4], organic light emitting diodes [5], and organic field-effect transistors [6]. The interactions between TMPc and different solid surfaces have been intensively investigated by many techniques. Scanning tunneling microscopy (STM) has been proven a powerful technique for studying the geometric conformations of TMPc molecules on solid surfaces owning to the capability of high spatial resolution [7-10]. In particular, the chirality of self-assembled structures of the achiral TMPc molecules deposited on solid surfaces has been a hot topic in recent years [11-16]. Highly symmetric molecules adsorbed on a substrate with dissimilar point-group symmetry have also been shown to develop chirality through asymmetric intermolecular interactions [14,15].

So far, significant progress has been achieved in the adsorption and self-assembly of various TMPc on either noble metal surfaces such as $\mathrm{Au}$ [17-23], $\mathrm{Ag}$ [16,24-26], $\mathrm{Cu}$ [27-32], Pb [19,33-35], or inert insulating surfaces such as $\mathrm{NaCl}$ [36-38]. In the former case, the large electron density of state (DOS) at the Fermi level leads to the molecule-substrate interactions which can modify the electronic structure and magnetic properties of TMPc. In the latter case, it is possible for TMPc molecules to be charged by the tunneling electrons from STM tip such that intrinsic spin state of TMPc would be altered. An intermediate case is between the two extreme regimes such as the semi-metallic Bi(111) surface, where molecule-substrate interactions are weaker than those for metallic substrates while the charging events of TMPc molecules would be avoided. It was reported recently that pentacene grown on the semi-metallic $\mathrm{Bi}(111)$ substrate forms epitaxial crystalline films with the pentacene 
molecule standing-up even in the first monolayer [39] rather than the planar orientation on $\mathrm{Au}(111)$ [40], indicating the weaker molecule-substrate interactions. In addition, the isolated molecule magnet $\mathrm{Mn}_{12}$ without any damage was successfully grafted onto the Bi(111) surface by the tip-depositing method [41]. However, so far, investigations on the structural evolution of TMPc on semi-metallic surface from isolated TMPc molecules to full monolayer, and finally to multilayer regime, remain too rare.
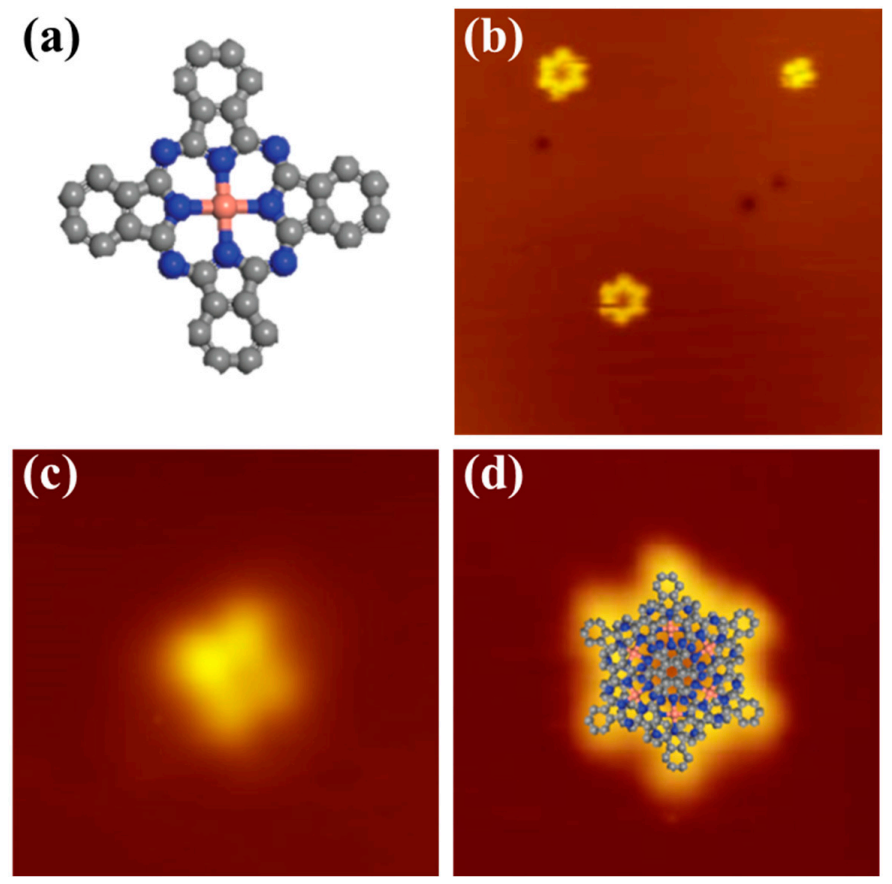

Figure 1. (a) Schematic structure model of the CuPc molecule; (b) STM image of isolated CuPc molecules in stationary and rotational state at $78 \mathrm{~K}, 25 \times 25 \mathrm{~nm},-2.0 \mathrm{~V}, 28 \mathrm{pA}$; (c) High-resolution STM image of a stationary CuPc molecule, $5 \times 5 \mathrm{~nm},-1.0 \mathrm{~V}, 26 \mathrm{pA}$; (d) High-resolution STM image of a rotating CuPc molecule, $5 \times 5 \mathrm{~nm},-2.8 \mathrm{~V}, 28 \mathrm{pA}$. The structural model for the six stable orientations of $\mathrm{CuPc}$ molecules are superposed on the STM image.

In this paper, we present the off-center rotation of a single $\mathrm{CuPc}$ molecule on the $\mathrm{Bi}(111)$ surface at $\mathrm{LN}_{2}$ temperature, indicating the weak molecule-semimetal interaction. In the $2 \mathrm{D}$ self-assembled domains, the achiral CuPc molecules reveal a chiral feature such that the four phthalocyanines lobes become bent. The chiral feature of $\mathrm{CuPc}$ molecules can be attributed to the combined effect of symmetric charge transfer between $\mathrm{CuPc}$ molecules and $\mathrm{Bi}(111)$ substrate and the intermolecular van der Waals (vdW) interactions. Furthermore, the orientation change-from lying flat in sub-monolayer regime to standing up in multilayer regime-occurred due to the enhanced intermolecular interactions compared with the molecule-substrate interactions.

\section{Results and Discussion}

Firstly, a small amount of CuPc molecules about 0.03 monolayer (ML) were deposited onto the $\mathrm{Bi}(111)$ surface at room temperature (RT). Isolated CuPc molecules in stationary or rotational state were observed from the STM image, as shown in Figure 1b. The stationary molecule appears as a cross shape with four perpendicular lobes and a dark hole located at the molecular center (the Cu ion site), consistent with the structure of CuPc molecule shown in Figure 1a. The dark hole of the CuPc center can be attributed to the occupied d-orbital character away from the Fermi energy of the copper ion. This differs from the previous reports about MnPc [42] on $\mathrm{Bi}(111)$ that the center of molecule appears as a bright protrusion. Figure $1 \mathrm{c}$ is a typical topographic image of an immobile CuPc molecule on the $\mathrm{Bi}(111)$ surface. It is noticed that the four lobes reveal different heights, implying a tilted adsorption 
with one lobe touching the substrate, like the rubrene molecule adsorbed on $\mathrm{Bi}(111)$ [43]. We speculate that the reason why this molecule remains immobile is that it is pinned by a substrate defect.

In the absence of defect, the individual CuPc molecules keep rotating around the touching site, which serve as the off-center rotational axis. Figure $1 \mathrm{~d}$ presents a disc-like $\mathrm{CuPc}$ molecule, which differs from the inherent cross-like molecular structure in Figure 1a, indicating that the individual $\mathrm{CuPc}$ molecule keeps off-center rotating on the Bi(111) surface. As a result, the four lobes of the $\mathrm{CuPc}$ molecule cannot be resolved from the STM image. The ring structure clearly exhibits a six-fold symmetry and the diameter of the rotating molecule is about $2.8 \mathrm{~nm}$, which is too large for a single immobile $\mathrm{CuPc}$ molecule. The insert in Figure $1 \mathrm{~d}$ shows the structural model of the rotating molecule. The observed molecular rotations indicate a weak molecule-substrate interaction between CuPc and $\mathrm{Bi}(111)$, whereas on noble metal substrates the molecular rotation is absent due to the considerable molecule-substrate coupling.

With molecular coverage increasing, isolated $\mathrm{CuPc}$ molecules began to assemble together on the $\operatorname{Bi}(111)$ surface, forming a series of nanoclusters-such as dimer, tetramer, hexamer, molecular chain, etc. Figure 2a shows a CuPc dimer with each monomer appearing as cross shapes consistent with its chemical structure in Figure 1a. It is noticed that the molecular rotation was absent when individual CuPc molecules assembled into clusters because of the additional van der Waals interactions between $\mathrm{CuPc}$ molecules. Figure $2 \mathrm{~b}, \mathrm{c}$ presents a tetramer and pentamer, respectively. Figure $2 \mathrm{~d}$,e exhibits the $\mathrm{CuPc}$ hexamer and octamer consisting of two parallel molecular chains. Furthermore, it is observed from the high-resolution STM images that the two opposing lobes of each CuPc molecule still remain in the directions of principal axis of the $\mathrm{Bi}(111)$ substrate. The alignment of the CoPc chains is also parallel to the principal axes of the Bi(111) lattice, similar to the CoPc chain adsorbed on $\mathrm{Bi}(111)$ [44]. It indicates that the molecule-substrate interaction is not negligible, which may arise from the surface states of the Bi(111) substrate.
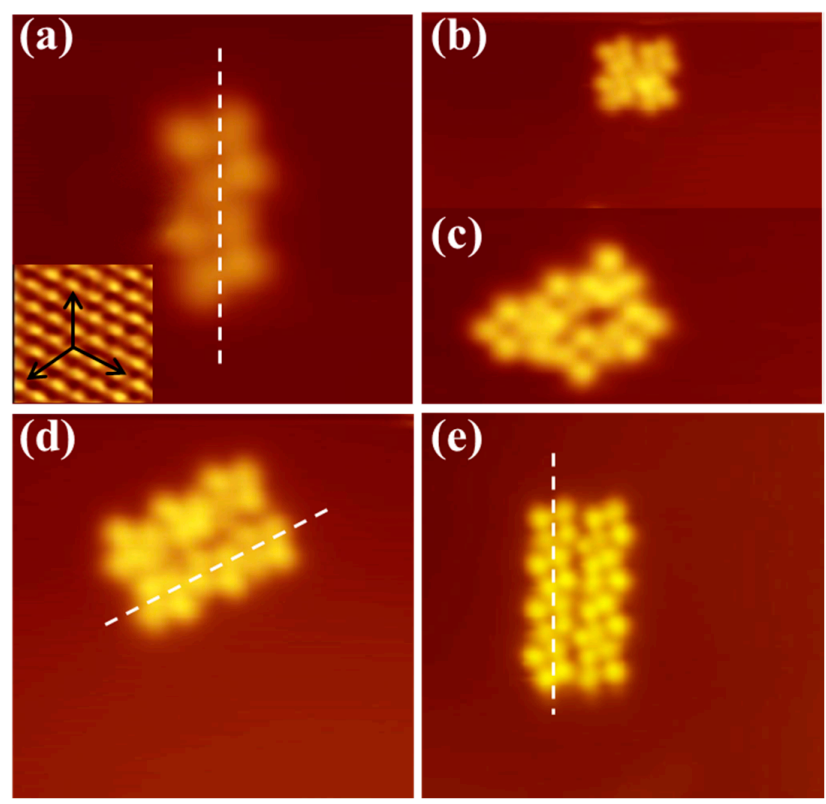

Figure 2. (a) A CuPc dimer adsorbed on the Bi(111) surface without any rotation, the arrows and dashed line represent the directions of $\mathrm{Bi}(111)$ surface base vectors, $6 \times 6 \mathrm{~nm},-1.7 \mathrm{~V}, 30 \mathrm{pA} ;(\mathbf{b}, \mathbf{c})$ are the STM images of CuPc tetramer and pentamer, respectively; (d) STM image of a CuPc hexamer consists of two parallel molecular chains along one of the high symmetry directions of the substrate, $10 \times 10 \mathrm{~nm},-1.7 \mathrm{~V}, 36 \mathrm{pA}$; (e) STM image of a CuPc octamer, $12 \times 12 \mathrm{~nm},-2.0 \mathrm{~V}, 30 \mathrm{pA}$.

When further depositing CuPc molecules on the Bi(111) surface, the individual molecular chains aggregated into 2D domains with parallel arrangement. Figure 3a,b shows the STM images of CuPc 
assembled films in the coverage of $0.75 \mathrm{ML}$ acquired at $-1.4 \mathrm{~V}$ and $+0.5 \mathrm{~V}$, respectively. It is observed that each $\mathrm{CuPc}$ molecule of the 2D domain exhibits a cross shape with four perpendicular lobes, consistent with the four-fold symmetry of $\mathrm{CuPc}$ molecular structure. This means that the $\mathrm{CuPc}$ molecules adopt a flat-lying adsorption orientation. Figure $3 \mathrm{c}$ displays the structural model of the 2D domains, the lattice constants of the unit cell are $\mathrm{a}_{1}=(1.42 \pm 0.02) \mathrm{nm}, \mathrm{b}_{1}=(1.35 \pm 0.02) \mathrm{nm}$, and $\mathrm{a}_{1}$ is aligned at one of the three principal axes of the $\operatorname{Bi}(111)$ surface. The angle $\alpha$ between $a_{1}$ and $b_{1}$ is measured to be $89^{\circ} \pm 2^{\circ}$ corresponding with a packing density of $0.52 \mathrm{~nm}^{-2}$, which is smaller than that of CoPc 2D domain on the Bi(111) substrate. Unlike MnPc and CoPc, 2D domains consisting of two different molecular orientations on the Bi(111) surface, the self-assembled CuPc 2D domains have identical in-plane orientations due to the mutual coupling of the symmetry of $\mathrm{Bi}(111) \mathrm{and} \mathrm{CuPC}$ molecules. The apparent Morié fringes are also observed from the STM image in Figure 3d, which shows the epitaxial growth for CuPc molecules on the semimetal bismuth substrate.
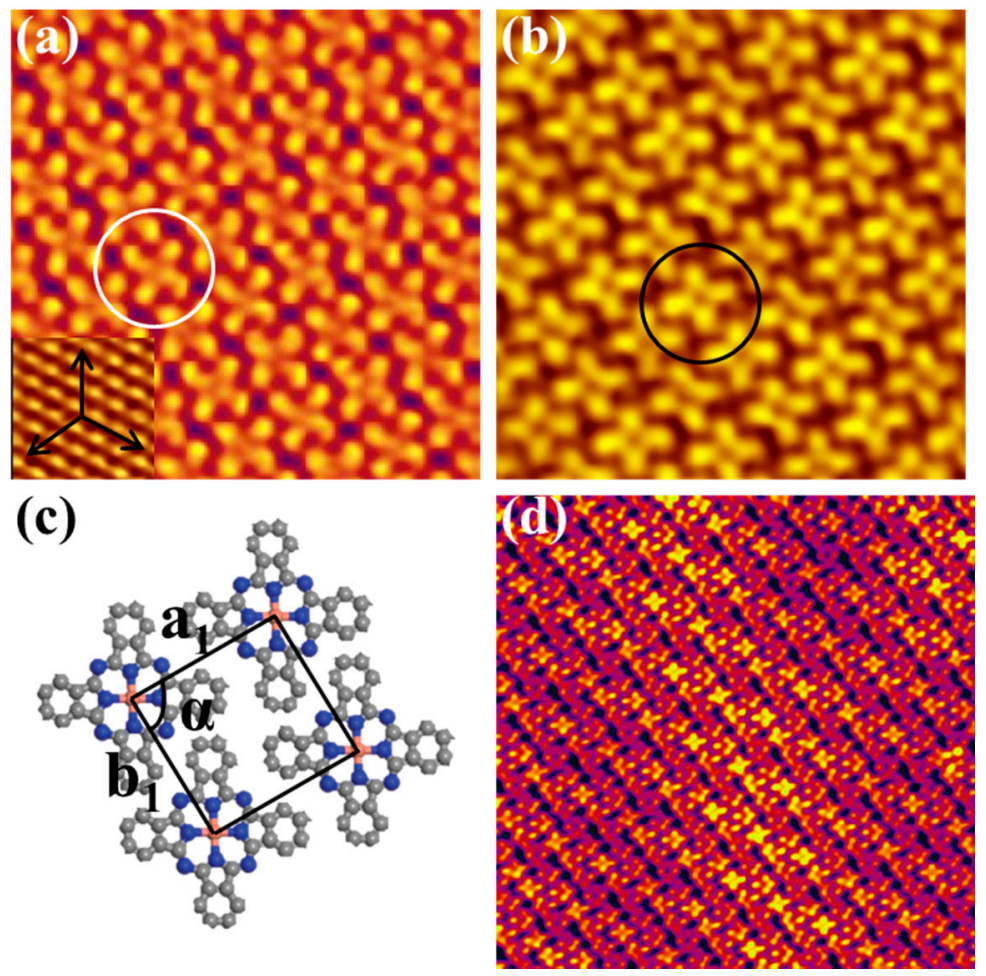

Figure 3. (a) Chiral feature appeared in the filled state STM image of the two-dimensional domains, $15 \times 15 \mathrm{~nm},-1.4 \mathrm{~V}, 28 \mathrm{pA}$; (b) Chiral feature disappeared essentially in the empty state STM image of the $2 \mathrm{D}$ domains, $10 \times 10 \mathrm{~nm},+0.5 \mathrm{~V}, 28 \mathrm{pA}$; (c) The structural model of the flat-lying 2D domain; (d) Morié fringe observed in the $2 \mathrm{D}$ domain of $\mathrm{CuPc}, 30 \times 30 \mathrm{~nm},-2.0 \mathrm{~V}, 28 \mathrm{pA}$.

More interestingly, the $\mathrm{CuPc}$ molecules of the 2D domain reveal different features under positive and negative bias voltage. Figure $3 \mathrm{a}$ is a STM image acquired at $-1.4 \mathrm{~V}$ that all the CuPc molecules exhibit a strong chiral feature, especially for the CuPc molecule marked by the while circle. The two opposing lobes of each $\mathrm{CuPc}$ molecule are twisted toward opposite directions, revealing the asymmetric intermolecular vdW interactions. However, the chiral feature disappears in the STM image in Figure 3b obtained at $+0.5 \mathrm{~V}$. This phenomenon is similar to $\mathrm{CuPc} / \mathrm{Ag}$ (100) system [24], but different from the $\mathrm{MnPc}$ and $\mathrm{CoPc}$ molecules. The latter reveals no chirality at both positive and negative bias voltage in 2D domains on the Bi(111) surface $[42,44]$. The voltage-dependent chiral appearance indicates that the original effect of molecular chirality is not a molecular geometric effect, but an electronic effect. The formation mechanism can be attributed to the combined effect of asymmetric charge transfer between $\mathrm{CuPc}$ molecules and $\mathrm{Bi}(111)$ substrate and the asymmetric intermolecular vdW interactions. 
In order to investigate the structural evolution of $\mathrm{CuPc}$ molecules in the multilayer regime, more $\mathrm{CuPc}$ molecules were deposited onto the substrate at RT subsequently. When the molecular coverage exceeds $1 \mathrm{ML}$, the second CuPc layers were achieved on the surface. Figure 4a is the high-resolution STM image of the second layer, in which each CuPc molecule adopts the standing-up adsorption orientation, rather than the planar orientation of the underlying layer. Figure $4 \mathrm{~b}$ is the zoomed-in STM image of the second CuPc layer, it can be observed that the pure domain is composed of several parallel molecular chains, in which each $\mathrm{CuPc}$ molecules adopts the face to face alignment. The distance of the CuPc molecules in the same chain is smaller than that in the neighboring chains, indicating that the intermolecular interactions for the former case are obviously stronger than the latter case. The structural model of unit cell of the second layer thin film is displayed in Figure 4c. The lattice constant are $\mathrm{a}_{2}=(1.18 \pm 0.02) \mathrm{nm}, \mathrm{b}_{2}=(0.45 \pm 0.02)$ $\mathrm{nm}$, and $\mathrm{a}_{2}$ is parallel to one of the three principal axes of the $\mathrm{Bi}(111)$ surface. The angle $\beta$ between $\mathrm{a}_{2}$ and $\mathrm{b}_{2}$ is measured to be $85^{\circ} \pm 2^{\circ}$ and the packing density is calculated to be $1.87 \mathrm{~nm}^{-2}$, which is $27.8 \%$ larger than that of the flat-lying CuPc layer. More importantly, an orientational transition from lying flat in the first layer to standing up in the second layer occurs due to the enhanced intermolecular interactions which can dominant the molecule-substrate interactions. Similar behavior was observed for $\mathrm{SnPc}$ adsorption on $\mathrm{NaCl}$, intermolecular interactions dominate over the molecule- $\mathrm{NaCl}$ coupling and result in a tilted adsorption configuration [45].
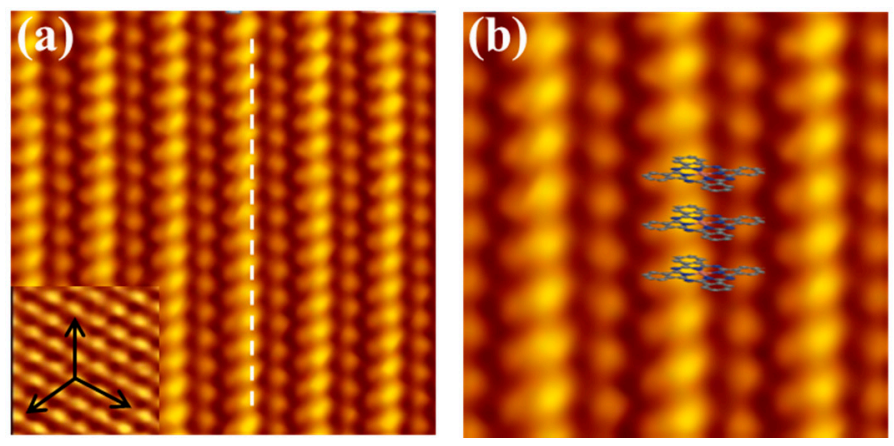

(c)

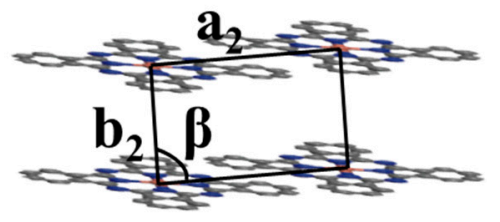

Figure 4. (a) High resolution STM image of the second layer of CuPc films consist of parallel standing-up CuPc chains, $7 \mathrm{~nm} \times 7 \mathrm{~nm},-0.8 \mathrm{~V}, 28 \mathrm{pA}$; (b) Zoomed-in STM image of the second layer domain, in which the CuPc molecules are marked by the superposed structural models; (c) The structural models of the unit cell in domain (a).

\section{Experiment Section}

The experiments were carried out in a Unisoku low-temperature STM system with base pressure $1.0 \times 10^{-10}$ Torr. The flat and well-ordered Bi(111) film was prepared by depositing 20 monolayers of bismuth atoms on a Si(III) $7 \times 7$ surface at RT with subsequent annealing at $400 \mathrm{~K}$ for nearly $2.5 \mathrm{~h}$ [46]. After overnight degassing, CuPc molecules (Sigma-Aldrich, St. Louis, MO, USA. 99\% purity) were thermally sublimated from a homemade Ta boat heated to about $480 \mathrm{~K}$ and then were deposited onto $\mathrm{Bi}(111)$ film at a rate of $0.45 \mathrm{ML}$ (here we define $1 \mathrm{ML}$ as the amount of deposited CuPc molecules cover entirely the substrate surface) per minute while the substrate was kept at RT. A constant current mode and polycrystalline tungsten tips after e-beam heating in the molecular beam epitaxy (MBE) chamber were used for STM imaging. All the STM images were obtained at liquid nitrogen temperature (78 K).

\section{Conclusions}

In summary, we have observed the molecular rotors of CuPc molecules with an off-center axis on a semi-metallic Bi(111) surface. The rotation axis is located at the end of a phthalocyanine group. The off-center rotation of $\mathrm{CuPc}$ molecules can be attributed to the tilted adsorption of CuPc molecule on Bi(111) surface. Furthermore, the chiral feature has also been found in the filled state STM image of the achiral CuPc molecules, which demonstrates that the chirality arising from the combined effect 
of asymmetric charge transfer between CuPc molecules and $\mathrm{Bi}(111)$ substrate and the asymmetric intermolecular vdW interactions.

Acknowledgments: This work was supported by the National Natural Science Foundation of China (Grant Nos. 11574253, 11604269, 61674123) and the Fundamental Research Funds for the Central Universities (XDJK2017C064).

Author Contributions: Kai Sun and Jun-Zhong Wang conceived and designed the experiments; Kai Sun and Min-Long Tao performed the experiments; Kai Sun and Yu-Bing Tu analyzed the data; Kai Sun, Min-Long Tao, and Yu-Bing Tu contributed reagents/materials/analysis tools; Kai Sun and Jun-Zhong Wang wrote the paper.

Conflicts of Interest: The authors declare no conflict of interest.

\section{References}

1. Bekaroglu, O.; Bian, Y.; Bottari, G.; Cai, X.; de la Torre, G.; Hahn, U.; Ishikawa, N.; Jiang, J.; Kobayashi, N.; Li, X.; et al. Functional Phthalocyanine Molecular Materials; Springer: Berlin, Germany, 2010.

2. Joachim, C.; Gimzewski, J.K.; Aviram, A. Electronics using hybrid-molecular and mono-molecular devices. Nature 2000, 408, 541-548. [CrossRef] [PubMed]

3. Moth-Poulsen, K.; Bjornholm, T. Molecular electronics with single molecules in solid-state devices. Nat. Nanotechnol. 2009, 4, 551-556. [CrossRef] [PubMed]

4. Peumans, P.; Yakimov, A.; Forrest, S.R. Small molecular weight organic thin-film photodetectors and solar cells. J. Appl. Phys. 2003, 93, 3693-3723. [CrossRef]

5. Blochwitz, J.; Pfeiffer, M.; Fritz, T.; Leo, K. Low voltage organic light emitting diodes featuring doped phthalocyanine as hole transport material. Appl. Phys. Lett. 1998, 73, 729-731. [CrossRef]

6. Lunt, R.R.; Benziger, J.B.; Forrest, S.R. Growth of an ordered crystalline organic heterojunction. Adv. Mater. 2007, 19, 4229-4233. [CrossRef]

7. Berner, S.; de Wild, M.; Ramoino, L.; Ivan, S.; Baratoff, A.; Guntherodt, H.-J.; Suzuki, H.; Schlettwein, D.; Jung, T.A. Adsorption and two-dimensional phases of a large polar molecule: Sub-phthalocyanine on Ag(III). Phys. Rev. B 2003, 68, 115410. [CrossRef]

8. Takada, M.; Tada, H. Low temperature scanning tunneling microscopy of phthalocyanine multilayers on Au(111) surfaces. Chem. Phys. Lett. 2004, 392, 265-269. [CrossRef]

9. Mannsfeld, S.C.B.; Fritz, T. Understanding organic-inorganic heteroepitaxial growth of molecules on crystalline substrates: Experiment and theory. Phys. Rev. B 2005, 71, 235405. [CrossRef]

10. Koudia, M.; Abel, M.; Maurel, C.; Bliek, A.; Catalin, D.; Mossoyan, M.; Mossoyan, J.C.; Porte, L. Influence of chlorine substitution on the self-assembly of zinc phthalocyanine. J. Phys. Chem. B 2006, 110, 10058-10062. [CrossRef] [PubMed]

11. Liu, J.; Chen, T.; Deng, X.; Wang, D.; Pei, J.; Wan, L.J. Chiral hierarchical molecular nanostructures on two-dimensional surface by controllable trinary self-Assembly. J. Am. Chem. Soc. 2011, 133, 21010-21015. [CrossRef] [PubMed]

12. Sun, R.R.; Wang, L.; Tian, J.; Zhang, X.M.; Jiang, J.Z. Self-assembled nanostructures of optically active phthalocyanine derivatives. Effect of central metal ion on the morphology, dimension, and handedness. Nanoscale 2012, 4, 6990-6996. [CrossRef] [PubMed]

13. Barlow, S.M.; Raval, R. Complex organic molecules at metal surfaces: Bonding, organisation and chirality. Surf. Sci. Rep. 2003, 50, 201-341. [CrossRef]

14. Schock, M.; Otero, R.; Stojkovic, S.; Hummelink, F.; Gourdon, A.; Laegsgaard, E.; Stensgaard, I.; Joachim, C.; Besenbacher, F. Chiral close-packing of achiral star-shaped molecules on solid surfaces. Phys. Chem. B 2006, 110, 12835-12838. [CrossRef] [PubMed]

15. Richardson, N.V. Adsorption-induced chirality in highly symmetric hydrocarbon molecules: Lattice matching to substrates of lower symmetry. New J. Phys. 2007, 9, 395. [CrossRef]

16. Mugarza, A.; Krull, C.; Korytar, R.; Lorente, N.; Gambardella, P. Electronic and magnetic properties of molecule-metal interfaces: Transition-metal phthalocyanines adsorbed on $\mathrm{Ag}(100)$. Phys. Rev. B 2012, 85, 155437. [CrossRef]

17. Zhao, A.D.; Li, Q.X.; Chen, L.; Xiang, H.J.; Wang, W.H.; Pan, S.; Wang, B.; Xiao, X.D.; Yang, J.L.; Hou, J.G.; et al. Controlling the Kondo effect of an adsorbed magnetic ion through its chemical bonding. Science 2005, 309, 1542-1544. [CrossRef] [PubMed] 
18. Zhang, Y.Y.; Du, S.X.; Gao, H.J. Binding configuration, electronic structure, and magnetic properties of metal phthalocyanines on a $\mathrm{Au}(111)$ surface studied with ab initio calculations. Phys. Rev. B 2011, 84, 125446. [CrossRef]

19. Jiang, Y.H.; Xiao, W.D.; Liu, L.W.; Zhang, L.Z.; Lian, J.C.; Yang, K.; Du, S.X.; Gao, H.J. Self-assembly of metal phthalocyanines on $\mathrm{Pb}(\mathrm{III})$ and $\mathrm{Au}(111)$ surfaces at submonolayer coverage. J. Phys. Chem. C 2011, 115, 21750-21754. [CrossRef]

20. Hipps, K.W.; Lu, X.; Wang, X.D.; Mazur, U. Metal d-orbital occupation-dependent images in the scanning tunneling microscopy of metal phthalocyanines. J. Phys. Chem. 1996, 100, 11207-11210. [CrossRef]

21. Lu, X.; Hipps, K.W.; Wang, X.D.; Mazur, U. Scanning tunneling microscopy of metal phthalocyanines: $\mathrm{d} 7$ and d9 cases. J. Am. Chem. Soc. 1996, 118, 7197-7202. [CrossRef]

22. Gao, L.; Ji, W.; Hu, Y.B.; Cheng, Z.H.; Deng, Z.T.; Liu, Q.; Jiang, N.; Lin, X.; Guo, W.; Du, S.X.; et al. Site-specific kondo effect at ambient temperatures in iron-based molecules. Phys. Rev. Lett. 2007, 99, 106402. [CrossRef] [PubMed]

23. Tsukahara, N.; Shiraki, S.; Itou, S.; Ohta, N.; Takagi, N.; Kawai, M. Evolution of Kondo resonance from a single impurity molecule to the two-dimensional lattice. Phys. Rev. Lett. 2011, 106, 187201. [CrossRef] [PubMed]

24. Mugarza, A.; Lorente, N.; Ordejion, P.; Krull, C.; Stepanow, S.; Bocquet, M.L.; Fraxedas, J.; Ceballos, G.; Gambardella, P. Orbital specific chirality and homochiral self-assembly of achiral molecules induced by charge transfer and spontaneous symmetry breaking. Phys. Rev. Lett. 2010, 105, 115702. [CrossRef] [PubMed]

25. Mugarza, A.; Krull, C.; Robles, R.; Stepanow, S.; Ceballos, G.; Gambardella, P. Spin coupling and relaxation inside molecule-metal contacts. Nat. Commun. 2011, 2, 490. [CrossRef] [PubMed]

26. Wang, Y.; Kröger, J.; Berndt, R.; Hofer, W. Structural and electronic properties of ultrathin tin-phthalocyanine films on Ag(III) at the single-molecule level. Angew. Chem. 2009, 121, 1287-1291. [CrossRef]

27. Schaffert, J.; Cottin, M.C.; Sonntag, A.; Karacuban, H.; Bobisch, C.N.; Lorente, J.; Gauyacq, P.; Möller, R. Imaging the dynamics of individually adsorbed molecules. Nat. Mater. 2013, 12, 223-227. [CrossRef] [PubMed]

28. Lippel, P.H.; Wilson, R.J.; Miller, M.D.; Wöll, Ch.; Chiang, S. High-resolution imaging of copper phthalocyanines by scanning tunneling microscopy. Phys. Rev. Lett. 1989, 62, 171-174. [CrossRef] [PubMed]

29. De Oteyza, D.G.; El-Sayed, A.; Garcia-Lastra, J.M.; Goiri, E.; Krauss, T.N.; Turak, A.; Barrena, E.; Dosch, H.; Zegenhagen, J.; Rubio, A. Copper-phthalocyanine based metal-organic interfaces: The effect of fluorination, the substrate, and its symmetry. J. Chem. Phys. 2010, 133, 214703. [CrossRef] [PubMed]

30. Tsukahara, N.; Noto, K.; Ohara, M.; Shiraki, S.; Takagi, N.; Takata, Y.; Miyawaki, J.; Taguchi, M.; Chainani, A.; Shin, S.; et al. Adsorption-induced switching of magnetic anisotropy in a single iron(II) phthalocyanine molecule on an oxidized Cu(110) surface. Phys. Rev. Lett. 2009, 102, 167203. [CrossRef] [PubMed]

31. Cuadrado, R.; Cerdá, J.I.; Wang, Y.; Xin, G.; Berndt, R.; Tang, H. CoPc adsorption on Cu(III): Origin of the C4 to C2 symmetry reduction. J. Chem. Phys. 2010, 133, 154701. [CrossRef] [PubMed]

32. Heinrich, B.W.; Iacovita, C.; Brumme, T.; Choi, D.J.; Limot, L.; Rastei, M.V.; Hofer, W.A.; Kortus, J.; Bucher, J.P. Direct observation of the tunneling channels of a chemisorbed molecule. J. Phys. Chem. Lett. 2010, 1, 1517-1523. [CrossRef]

33. Hao, D.; Song, C.; Ning, Y.; Wang, Y.; Wang, L.; Ma, X.C.; Chen, X.; Xue, Q.K. Self-assembly of manganese phthalocyanine on $\mathrm{Pb}(\mathrm{III})$ surface: A scanning tunneling microscopy study. J. Chem. Phys. 2011, 134, 154703. [CrossRef] [PubMed]

34. Fu, Y.S.; Ji, S.H.; Chen, X.; Ma, X.C.; Wu, R.; Wang, C.C.; Duan, W.H.; Qiu, X.H.; Sun, B.; Zhang, P.; et al. Manipulating the Kondo resonance through quantum size effects. Phys. Rev. Lett. 2007, 99, 256601. [CrossRef] [PubMed]

35. Chen, X.; Fu, Y.S.; Ji, S.H.; Zhang, T.; Cheng, P.; Ma, X.C.; Zou, X.L.; Duan, W.H.; Jia, J.F.; Xue, Q.K. Probing super exchange interaction in molecular magnets by spin-flip spectroscopy and microscopy. Phys. Rev. Lett. 2008, 101, 197208. [CrossRef] [PubMed]

36. Swart, I.; Sonnleitner, T.; Repp, J. Charge state control of molecules reveals modification of the tunneling barrier with intramolecular contrast. Nano Lett. 2011, 11, 1580-1584. [CrossRef] [PubMed]

37. Uhlmann, C.; Swart, I.; Repp, J. Controlling the orbital sequence in individual Cu-phthalocyanine molecules. Nano Lett. 2013, 13, 777-780. [CrossRef] [PubMed]

38. Wu, S.W.; Nazin, G.V.; Chen, X.; Qiu, X.H.; Ho, W. Control of relative tunneling rates in single molecule bipolar electron transport. Phys. Rev. Lett. 2004, 93, 236802. [CrossRef] [PubMed] 
39. Hirahara, T.; Nagao, T.; Matsuda, I.; Bihlmayer, G.; Chulkov, E.V.; Koroteev, Y.M.; Echenique, P.M.; Saito, M.; Hasegawa, S. Role of spin-orbital coupling and hybridization effects in the electronic structure of ultrathin Bi film. Phys. Rev. Lett. 2006, 97, 146803. [CrossRef] [PubMed]

40. Thayer, G.E.; Sadowski, J.T.; Heringdorf, F.M.Z.; Sakurai, T.; Tromp, R.M. Role of surface electronic structure in thin film molecular ordering. Phys. Rev. Lett. 2005, 95, 256106. [CrossRef] [PubMed]

41. Sun, K.; Park, K.; Xie, J.L.; Luo, J.Y.; Yuan, H.K.; Xiong, Z.H.; Wang, J.Z.; Xue, Q.K. Direct observation of molecular orbitals in an individual single-molecule magnet $\mathrm{Mn}_{12}$ on $\mathrm{Bi}(111)$. ACS Nano 2013, 7, 6825-6830. [CrossRef] [PubMed]

42. Zhang, T.T.; Wang, C.J.; Sun, K.; Yuan, H.K.; Wang, J.Z. Step-by-step self-assembly of manganese phthalocyanine on Bi(111) surface: From single molecule to two-dimensional domains. Appl. Surf. Sci. 2014, 317, 1047-1051. [CrossRef]

43. Lan, M.; Xiong, Z.H.; Li, G.Q.; Shao, T.N.; Xie, J.L.; Yang, X.F.; Wang, J.Z.; Liu, Y. Strain-driven formation of rubrene crystalline films on $\mathrm{Bi}(001)$. Phys. Rev. B 2011, 83, 195322. [CrossRef]

44. Tao, M.L.; Tu, Y.B.; Sun, K.; Zhang, Y.; Zhang, X.; Li, Z.B.; Hao, S.J.; Xiao, H.F.; Ye, J.; Wang, J.Z. Structural transitions in different monolayers of cobalt phthalocyanine film grown on Bi(111). J. Phys. D Appl. Phys. 2016, 49, 015307. [CrossRef]

45. Wang, Y.F.; Kroger, J.; Berndt, R.; Tang, H. Molecular Nanocrystals on Ultrathin NaCl Films on Au(111). J. Am. Chem. Soc. 2010, 132, 12546-12547. [CrossRef] [PubMed]

46. Nagao, T.; Sadowski, J.T.; Saito, M.; Yaginuma, S.; Fujikawa, Y.; Kogure, T.; Ohno, T.; Hasegawa, Y.; Hasegawa, S.; Sakurai, T. Nanofilm allotrope and phase transformation of ultrathin Bi film on $\mathrm{Si}(\mathrm{III})-7 \times 7$. Phys. Rev. Lett. 2004, 93, 105501. [CrossRef] [PubMed]

Sample Availability: Not available.

(C) 2017 by the authors. Licensee MDPI, Basel, Switzerland. This article is an open access article distributed under the terms and conditions of the Creative Commons Attribution (CC BY) license (http://creativecommons.org/licenses/by/4.0/). 